\section{Carol Livingstone}

Role play in language learning. Harlow: Longman, 1983. (94 pp.)

In the past decade, the communicative approach to second language teaching has been the subject of unprecedented attention and research and already many claims have been made for its success. Several books by applied linguists have attempted to trace its development and explain its theoretical basis. Although a few language textbooks based on the communicative approach have also been published, some language teachers still have doubts about its practical implementation in the classroom, while many more confess to be at a loss as to how to meet the demands of a so-called "communicative syllabus". This is particularly true of teachers of English second language in South Africa, where a new communication-based syllabus is to be introduced for English L2 at secondary school level in 1986. Without doubt most teachers would welcome a book which not only lists several communicative activities, but also discusses, in practical terms, various ways of presenting these in the language classroom.

To a large extent, Carol Livingstone's book will meet these needs. As the title indicates, it concerns role play, but it would be wrong to assume that this is too limited a scope. Most teachers agree that, in order to achieve the student interaction essential to real communicative activities, some or other form of role play is usually required.

This book is a comprehensive guide to the use of role play in the classroom. Chapter 1 sets out to answer the question: What is role play? In doing so, it distinguishes between role play and other associated activities such as simulation, group work and dialogue work, thus providing the teacher with a workable frame of reference. Teachers more interested in practical examples will welcome Chapter 2 , for it describes and analyses two role plays, touching on such aspects as teacher preparation, class preparation and follow-up work at both beginners' and advanced levels.

While Chapter 3, like the first chapter, is mainly theoretical (discussing the advantages and disadvantages of using role play in the classroom), the next three chapters return to practical consider- ations. Chapter 4 provides a role play checklist which includes student needs, organisation and follow-up. Chapter 5 deals with long-term preparation under the following headings: formal oral practice; dialogue work; miming, games and drama; listening comprehension. Each activity is clearly illustrated with the use of specific examples.

This leads up to probably the most useful section, from the point of view of the teacher. Chapter 6 is devoted to developing role plays. It deals, among other things, with interviews and role play using a particular theme. The examples supplied are on three levels: beginners', intermediate and advanced, and should prove useful to the novice as well as the experienced teacher. The chapter ends with detailed explanations of how to exploit existing role play material and how to create one's own. Finally, an appendix provides role play ideas at all three levels mentioned above.

Carol Livingstone points out that there are still a number of problems to be solved, notably "the teaching and learning of para- and extra-linguistic features, and the question of the acceptability and appropriateness of utterances in any given context and situation." Nevertheless, her book provides much needed practical information on the use of role play in the classroom and its integration into the total language learning programme. Teachers should welcome its direct approach to the subject, its clear organization, its conciseness and its many examples. It should prove an invaluable aid to the second language teacher in search of ideas and ways of implementing a communicative syllabus.

\section{J.J. Swartz}

Department of English

Faculty of Éducation

University of Stellenbosch

7600 Stellenbosch

Republic of South Africa

\section{Ann Raimes}

Techniques in teaching writing. New York: Oxford University Press, 1983. (164 pp.)

This book forms part of the series, Teaching Techniques in English as a Second Language. Like 
others in the series, it is aimed at meeting the need felt by both practising and student teachers for theoretically well-grounded help with classroom practice.

What teachers want are useful ideas, suggestions, demonstrations, and examples of teaching techniques that have proven successful in the classroom-techniques that are consistent with established theoretical principles and that others in our profession have found to be expedient, practical, and relevant to the real-life circumstances in which most teachers work.

Those who know Professor Raimes's Focus on composition will not be surprised that she was chosen to discuss the teaching of writing.

The organization of the book makes it very easy to use. It is neatly divided into nine chapters with selfexplanatory titles: Introduction; Teaching writing in ESL classes; Techniques in planning the class: Seven basic questions; Techniques in using pictures; Techniques in using readings; Techniques in using all the language skills; Techniques in teaching practical writing; Techniques in using controlled writing; Techniques in teaching organization; and Techniques in responding to students' writing. For those who wish to explore the ideas and suggestions made, there are notes for each of the chapters as well as a carefully selected bibliography at the end of the book.

Chapter 1 provides a succinct overview of teaching writing in ESL classes, discussing such aspects as the reason for teaching writing, some of the differences between speech and writing, and the main approaches used in teaching writing. Professor Raimes is sensibly eclectic, emphasizing that "writing means writing a connected text and not just single sentences, that writers write for a purpose and a reader, and that the process of writing is a valuable learning tool for all our students" (p. 11).

Chapter 2 presents the teacher with seven basic questions which he can use in evaluating and select- ing the techniques that will be most effective in his particular situation. Each question in turn is discussed; revealing Professor Raime's practical understanding of the difficulties and challenges which face the ESL teacher. Detailed suggestions are made, showing how, for instance, a dull textbook topic can give rise to a series of activities "that will help prepare students for the assignment and give them the opportunity to speak, listen to, read and write the new language in the process of making and communicating their meaning" (p. 13). She clearly does not see writing as a discrete activity.

I found her discussion of question 7 (What do I do about errors?) particularly lucid. Classroom practice has generally not yet taken account of the findings of error analysis and so teachers tend to be engaged in a search for errors. Professor Raimes provides a sound, coherent rationale for a different approach within the context of communicative teaching.

The other seven chapters are organized in a similar way. In each case there is a careful discussion of the value of the teaching resource, general strategies that could be usefully adopted, and then detailed consideration of appropriate techniques. At the end of each chapter there is a list of activities which teachers can use to develop or practise the techniques learnt in the book.

Some of the suggested activities are a little dull, and the ethos of the book is American. These are minor criticisms in the light of the excellent teaching that is to be found in this book. I warmly recommend it to language teachers who would like to increase the effectiveness of their teaching, particularly those whose training did not take "communicative" methods into account.

\section{E. Ridge}

Department of English

Faculty of Education

University of Stellenbosch

7600 Stellenbosch

Republic of South Africa 